\title{
A conceptual framework of the relationship between musicking and Personal and Social Well-being for intermediate phase learners in the South African context
}

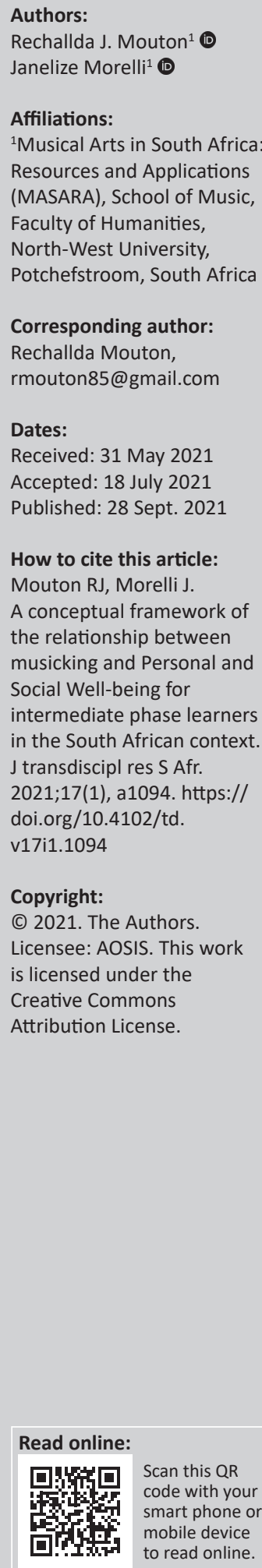

This article proposes a conceptual framework to understand the relationship between musicking and Personal and Social Well-being for intermediate phase learners. We analysed the intermediate phase life skills Curriculum and Assessment Policy Statement (CAPS) document to create a priori codes. We employed these codes to analyse literature on musicking and well-being. Through this analysis, it became clear that it is possible to apply musicking as a means to teach Personal and Social Well-being outcomes in the intermediate phase life skills CAPS provided teachers view musicking as cultural and moral education. This article presents a conceptual framework resting on nine propositions that need to be addressed if teachers wish to teach personal and social well-being through musicking.

Keywords: South Africa; life skills; intermediate phase; well-being; conceptual framework; musicking; music education.

\section{Introduction}

Although there are studies that seek to investigate the creative arts section in life skills during the intermediate phase, as set out in the Curriculum and Assessment Policy Statement (CAPS) syllabus, and studies that investigate the personal and social well-being section of the life skills curriculum, we are not aware of any studies which investigate the integration of these two sections in the intermediate phase in the South African context. Therefore, it is the purpose of this conceptual study to create a conceptual framework to understand the integration of music, in particular, and personal well-being in the intermediate phase. We synthesised this framework by following three steps: (1) creating a priori codes from the CAPS syllabus (particularly from the personal and social well-being section in the intermediate phase); (2) analysing applicable scholarly literature on music education, community music and wellbeing to create a conceptual framework which might indicate how teachers may effectively integrate these two areas in the intermediate phase life skills classroom and (3) interpreting these findings through applicable theoretical or conceptual lenses to create a rich framework. Our findings culminate in a conceptual framework for teaching Personal and Social Well-being through musicking.

\section{Literature review}

Teachers are pivotal agents in creating a safe space in which learners may experience personal well-being and engage in musicking. In this article, we will use the term 'musicking' to refer to a view of music not as a noun, but as a verb. Musicking refers to any musical contribution including, but not limited to, performing, listening, improvising, composing and moving to music. ${ }^{1}$ Furthermore, Small ${ }^{1}$ views musicking as a means through which a specific community portrays the ideal form of human relationships within that society. Since the life skills subject area is comprised of personal and social well-being, physical education and creative arts, we assert that this view of musicking is particularly applicable to the context of life skills in the intermediate phase classroom.

Creating tailored music programmes may encourage the development of such caring relationships in the classroom. ${ }^{2}$ In the context of the intermediate phase life skills classroom, such a tailored music programme will focus on incorporating all three aspects to create a programme where the creative arts (and we argue music in specific) facilitates the teaching of personal and social well-being, and physical education. Throughout this article, we will be giving examples of the types of musicking which may be included in such a tailored music programme. There is also a section which draws 
together examples of ways in which the conceptual framework proposed in this article may be applied to create such a tailored music programme in the intermediate phase life skills classroom. Given the constraints set out by the length of an article, we will only focus on facilitating the personal and social well-being section of intermediate phase life skills. Carefully creating tailored music programmes may be particularly important in culturally diverse settings. ${ }^{3}$ In order to successfully deliver these tailored music programmes, it is paramount that teachers view themselves as facilitators for the kinds of relationships we wish to teach learners in the intermediate phase life skills classroom.

When teachers are empowered to view themselves as pivotal characters in the creation of strong social bonds between learners, they become artistic citizens. ${ }^{4,5}$ Artistic citizenship requires teachers to become more critically reflective about the actions they take in the classroom. It also requires active musicking in the classroom to be informed by such critical reflection. When teachers take on this active role as artistic citizens, it is possible to create strong relationships between them and their learners through positive interaction and musicking. Therefore, the teacher plays a vital role as an ethical agent in the education world. $^{6}$ Once teachers understand the role they play as ethical agents in the life skills classroom, they may be empowered to facilitate the personal and social well-being outcomes effectively through the use of active musicking.

Research indicates that individuals employ music to promote emotional, social and physical well-being. ${ }^{7}$ Music reduces anxiety $^{8}$ and therefore promotes personal well-being, which may promote learning as a result. Positive music education experiences may assist with self-management and development of school-aged children. ${ }^{9}$ Self-management refers to learners' ability to take responsibility for their actions and to understand which actions may contribute to positive outcomes and subjective well-being. Self-management skills learners in the intermediate phase may include learning to collaborate effectively, understanding the importance of rules to ensure that groups operate in a just manner, and developing a sense of responsibility. Self-management may be viewed as a skill which contributes to both emotional intelligence and self-regulation. Group music classes may aid students in developing self-management by placing an emphasis on positive collaboration and helping learners to become more self-reflective. This necessitates an approach to musicking in the life skills class built upon artistic citizenship, ${ }^{4,5}$ where both the teacher and the learners engage in active reflection through questions such as: What happened? What went well? Or, What were the challenges we experienced? And, What would I or we do differently next time?

Furthermore, when pupils collaborate creatively in instrumental group music, they experience well-being by engaging with other students. ${ }^{10}$ Improvising responses to a musical call is an activity which asks of learners to collaborate creatively with their peers. Other collaborative creative activities may include movement improvisation or movement mirroring to recorded music.
In another study, participation through musicking in an orchestra is shown to promote health and emotional wellbeing in children. ${ }^{11}$ Although orchestral musicking may not be feasible in many intermediate phase classrooms, learners could engage in other readily available musicking events such as expressing themselves through body percussion, beatboxing, playing on found instruments or participating in group singing. These studies point to the potentiality of music as a mechanism for well-being promotion in the intermediate phase life skills classroom.

In the South African context, the relationship between musicking and well-being is central, as creative arts is placed together with personal and social well-being in the life skills CAPS document. ${ }^{12}$ In our experience, even specialist music teachers in the intermediate phase are, however, often unfamiliar with the approaches one could take to integrate the different components of life skills. ${ }^{13}$ There is, therefore, a great need for awareness amongst music educators and general educators about the relationship between personal well-being and musicking, to ensure that they are able to integrate these two concepts in their own teaching. As of now, there is no conceptual framework in the literature which may be used to understand the relationship between personal well-being and musicking in the life of the intermediate phase child in the South African context.

It is our hope that this study will provide teachers with a conceptual framework that might empower them to teach in ways that promote the personal and social well-being of their students. Similarly, we hope that this research will be used by policymakers to inform the decisions they take at a macro-level.

\section{Research procedures}

The purpose of this conceptual study is to understand the relationship between musicking and personal well-being for intermediate phase learners (Grade 4-6). The research question that guided this study is: How can the emergent themes from the related literature be integrated to generate a conceptual framework to explain the relationship between personal well-being and musicking for intermediate phase learners?

Data were collected using the following search terms in academic search engines: musicking, personal well-being and life skills for grade 4-6 learners. During this initial search process, we analysed 12 articles on personal well-being and 11 on life skills. After the first cycle of analysis, it was clear that we had not yet reached data saturation. ${ }^{14}$ We consulted with various colleagues in the field of music for well-being and included any sources they deemed applicable which were not yet part of the data set. After these additional data were analysed, we reached data saturation. Because of the initial challenges in locating applicable scholarly literature, we used an iterative approach, tying the processes of data 
TABLE 1: A list of categories with their associated a priori codes and accompanying conceptual frames for interpretation.

\begin{tabular}{|c|c|c|}
\hline Category & A priori codes & $\begin{array}{l}\text { Conceptual frame } \\
\text { for interpretation } \\
\text { of findings }\end{array}$ \\
\hline $\begin{array}{l}\text { Cultural and } \\
\text { moral } \\
\text { education }\end{array}$ & $\begin{array}{l}\text { - Respect for own body } \\
\text { - Respect for others' bodies } \\
\text { - Responsibilities at home and school } \\
\text { - Children's responsibilities in relation to their } \\
\text { rights } \\
\text { - Cultural and moral lessons } \\
\text { - Moral lessons } \\
\text { - Concepts: Discrimination, stereotype and bias } \\
\text { - Caring for people } \\
\text { - Considering others' needs } \\
\text { - Acts of kindness towards other people } \\
\text { - Mediation skills } \\
\text { - Working in a group school and home } \\
\text { - Benefits of working in a group } \\
\text { - Relationships with peers }\end{array}$ & $\begin{array}{l}\text { Communitarianism } \\
\text { (ubuntu) }\end{array}$ \\
\hline $\begin{array}{l}\text { Emotional } \\
\text { intelligence }\end{array}$ & $\begin{array}{l}\text { - Identifying and respecting own and others' } \\
\text { character strengths } \\
\text { - Understanding a range of emotions } \\
\text { - Understanding own emotions } \\
\text { - How to consider and understand other's } \\
\text { emotions } \\
\text { - Responses to challenges in working in a group } \\
\text { - Positive self-concept formation } \\
\text { - Influence of others on self-concept } \\
\text { - Giving and receiving feedback } \\
\text { - Coping with emotions } \\
\text { - Skills to manage emotions } \\
\text { - Identifying own abilities } \\
\text { - Peer pressure } \\
\text { - Self-management } \\
\text { - Strategies to deal with abuse } \\
\text { - Violent situations at schools and homes } \\
\text { - Dealing with violent situations } \\
\text { - Responding to violent situations } \\
\text { - Conflict management strategies }\end{array}$ & $\begin{array}{l}\text { Ethically informed } \\
\text { emotional and social } \\
\text { competency } \\
\text { inventory }\end{array}$ \\
\hline $\begin{array}{l}\text { Fostering } \\
\text { well-being }\end{array}$ & $\begin{array}{l}\text { - Success experiences } \\
\text { - Safe and unsafe relationships } \\
\text { - Positive self-esteem: Body image } \\
\text { - Understanding and respecting body changes } \\
\text { - Acceptance of self } \\
\text { - Relationships amongst abilities, interests and } \\
\text { potential }\end{array}$ & PERMA framework \\
\hline
\end{tabular}

PERMA, positive emotion, engagement, relationships, meaning and accomplishment.

collection and analysis together in a cycle of repetition and refocussing.

The CAPS document for life skills intermediate phase personal and social well-being was analysed. ${ }^{12}$ From the analyses, a priori codes were created (see Table 1), which were used to analyse the literature identified throughout the data gathering stage. Because of the use of a priori codes, the data analysis employed a primarily deductive approach. ${ }^{15}$ For the purposes of this article, the performing arts CAPS was not analysed to create a priori codes. This may be seen as a limitation in this study.

After we completed the initial coding phase, we engaged in the process of consolidation and reinterpretation which eventually led to the creation of three categories. These

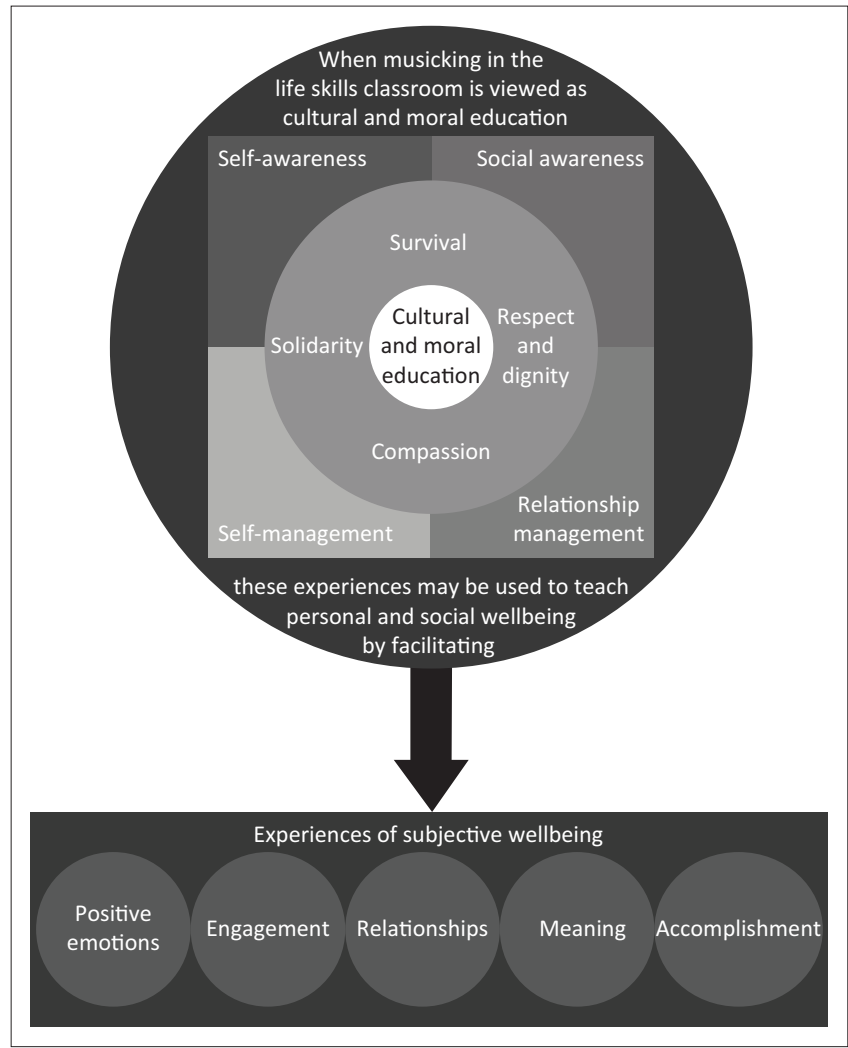

Source: Molose T, Goldman GA, Thomas P. Towards a collective-values framework of Ubuntu: Implications for workplace commitment. Entrepreneurial Bus Econ Rev. 2018;6(3):193-206. https://doi.org/10.15678/EBER.2018.060312

FIGURE 1: A conceptual framework for teaching personal and social well-being through musicking in the intermediate phase life skills class.

categories were: (1) cultural and moral education, emotional intelligence and (3) fostering well-being.

The findings are further interpreted through the lens of chosen theoretical or philosophical perspectives to elucidate the meaning of core concepts (Figure 1). The category of cultural and moral education is interpreted through the lens of ubuntu as described by Molose et al. ${ }^{16}$ This framework was chosen because it aligns well with the a priori codes in the category cultural and moral education. We ascribe this alignment to the general emphasis on respect for self and others, and the caring relationality described in the CAPS document. According to the collective-values of the ubuntu framework, the four values which serve as foundation for ubuntu are: survival, respect and dignity, compassion and solidarity.

Emotional intelligence is interpreted by making use of the ethically informed emotional and social competency inventory. ${ }^{17}$ We employ this framework because it places ethics at the centre of the framework of emotional intelligence, and views ethics as the foundational competency for developing the other four emotional competencies: selfawareness, social awareness, relationship management and self-management. As alluded previously, and illustrated through our findings, ethical and moral education also play a central role in our view of musicking in the intermediate phase life skills classroom. Therefore, this framework is appropriate to interpret our findings through. 
The positive emotion, engagement, relationships, meaning and accomplishment (PERMA) framework were employed, to understand what fostering well-being might entail. ${ }^{18}$ The PERMA framework posits a theory of the elements of subjective well-being. The elements included in this theory are PERMA. Seligman ${ }^{18}$ argues that the PERMA framework is appropriate for evaluating subjective well-being because the individual elements contribute to well-being and people strive towards these elements as ends to themselves. Each element may lead practitioners or individuals to specific interventions to address shortcomings in their experience of subjective well-being. These perspectives contribute value to our conceptual framework by illuminating the concepts within each category. These categories, along with the illuminated central concepts, were explored through a process of abduction used to create the conceptual framework. ${ }^{15}$

During this research study, we documented our steps carefully to create an audit trail. ${ }^{19}$ As we find ourselves positioned strongly within a social constructivist paradigm, ${ }^{14}$ we also made use of an interpretive community to help us negotiate the meaning which is presented in this conceptual framework. We would like to thank all the fellow researchers and graduate students in the Musical Arts in Africa: Research and Applications research niche at the North-West University for their participation in this social meaning-making process. We also adhered to the guidelines for research and academic integrity as set out by the North-West University.

\section{Findings}

This conceptual model is the culmination of our data analysis and reflection on the integration between musicking and personal and social well-being in the intermediate phase life skills classroom. In moral and cultural education, we found that the emphasis is on how we conduct ourselves and that music binds us together socially creating empathy for one another. The literature on emotional intelligence highlighted the ways in which musicking within a supportive environment could facilitate self-awareness and awareness of others. Therefore, musicking in the life skills classroom may contribute to fostering well-being by connecting us to others and ourselves, and creating a strong sense of self-awareness. The final theme, engaging in musicking for well-being, illustrates the ways in which an individual or a group of people may use musicking to achieve the elements of subjective well-being in the intermediate phase life skills classroom.

\section{Cultural and moral education through musicking in the life skills classroom}

During our analysis of the personal and social well-being section of the CAPS document, cultural and moral education stood out as an important category. Our understanding of the type of cultural and moral education advocated for in the CAPS document is influenced by Molose et al.'s $\mathrm{s}^{16}$ understanding of the values of ubuntu. Ubuntu is seen as an ethical and moral worldview where the survival of the group is dependent on complex reciprocal relationships.
Respect forms the basis of all social interaction and is posited as a possible central value to address diversity within contemporary society. Another central value in this view of ubuntu is compassion. Compassion is seen as a means of extending one's own experience to take the experience of others into consideration. This also means that leaders, or in our case life skills teachers, interact compassionately with those they lead by bearing witness to their experiences. The final value that Molose et al. ${ }^{16}$ identify as central to ubuntu is solidarity. This refers to the inextricable link between the individual and the collective. Therefore, institutions, such as schools, and collectives, such as the classrooms, serve the good of the members.

An analysis of the literature echoed the intertwined nature of music, cultural education and moral education. Ansdell ${ }^{20}$ states that our 'musical life world' is intertwined with our social and cultural ecology. Therefore, we argue that the integration of music outcomes and personal and social wellbeing outcomes in the intermediate phase CAPS document cannot ignore the role of music in cultural and moral education.

Firstly, there is an abundance of literature showing the role of music in cultural education. In this regard, we believe that music education as and for cultural education serves as a prime example of this phenomena. DeNora ${ }^{21}$ further addresses the instrumental value of music, and how people apply music in their daily lives.

Noddings ${ }^{22}$ defines moral education as 'referring to how we should conduct our lives and, especially, how we should interact with others'. We found in the data that there were many references to how we should conduct our lives in and through music with particular emphasis on the challenges faced by music educators in an increasingly unjust world. As such, social justice in music education has experienced a great deal of interest in recent years. Although social justice was not part of our keyword search, the values and call to action are echoed in the data.

Bunt ${ }^{23}$ states that we can tell untold stories through musicking together. This form of storytelling may be seen as an act of caring. Studies have shown that when musicians care for those they perform to, a reciprocal form of satisfaction springs forth from the caring musicking. ${ }^{20,24}$ Therefore, our conceptual framework indicated that actively musicking together with children may enhance empathy and expressions of care. ${ }^{24}$ Music creates a space for people to get to know one another, creating a safe and caring environment. ${ }^{20}$

Through musicking, people enact the idealised social relationships within their community. ${ }^{1}$ Music may speed up the process of building relationships and nurturing the other..$^{20}$ Thus musicking creates a space for discourse, exchange and cooperation in which the idealised form of social interaction may be expressed. ${ }^{1}$ Under the right conditions, the community ties expressed through musicking relationships may contribute to the well-being of group members. ${ }^{25}$ 
Therefore, if our ideal community ties are characterised by compassion and empathy, we need to enable learners to engage in musicking activities in which these kinds of ties are expressed. Research has shown that musical engagement produces empathy in children. ${ }^{25}$ Thus, musicking creates a sense of extendedness towards the other person in a nonthreatening way. ${ }^{20}$ Through this musical extension, learners and teachers in the intermediate phase life skills class may be able to reach intricate emotional spaces, which most other modalities cannot reach. ${ }^{26}$

\section{Cultivating emotional intelligence through musicking}

Our understanding of the type of emotional intelligence advocated for in the life skills CAPS document is influenced by an ethically informed emotional and social competency inventory. ${ }^{17}$ Such a view of emotional intelligence aligns with the emphasis on moral education in the CAPS document as it places ethics in the centre of what is understood to be emotional intelligence. Furthermore, this framework argues that emotional intelligence is the result of an individual displaying competency in self-awareness, social awareness, self-management and relationship management. These competencies relate closely to the outcomes in the CAPS document, and are also reflected in the literature on musicking and well-being.

Musicking refers to a process in which people engage within a specific socio-historic moment. ${ }^{20}$ When more than one person is engaged in a musicking activity, one may think of it as a dialogue with the intent of sharing ideas without having a preconceived notion of what outcome might be. The freedom entailed in this view of musicking opens up possibilities for teachers in the life skills classroom to employ musicking as a means to explore various aspects of emotional intelligence.

Musicking connects people to their deepest emotions and, subsequently, may lead to intense emotional experiences..$^{20,24}$ It awakens a mixture of emotions depending on the individual's emotional state of mind at the time. ${ }^{24}$ Whilst musicking, there is room and space for tolerance towards one another, and accepting and encouraging the emotional experiences of each other in a special way. ${ }^{20}$

There is a strong connection between relationship building and emotional literacy. By allowing space for the experience of different emotional realities, music positively affects our relationships. ${ }^{20,24}$ Emotional literacy directly influences relationships promoting mental health through the expression of creative ideas. ${ }^{27,28,29}$

Research indicates that individuals may employ music to alter their emotional states..$^{30}$ When children listen to music, they feel connected to others more easily. ${ }^{31}$ In return, these children could open up about their problems, as music transported them beyond their physical worlds. ${ }^{20,32}$ Thus, music can be used to positively enhance emotions. ${ }^{25}$
Musicking may also be employed to alter emotional states or as an active stress reduction strategy. ${ }^{33}$ Stress and tension are experiences which are very prevalent in our modern world. Through singing, people may be able to find relief from these emotions. ${ }^{34}$ Thus, musical interaction lowers the stress response in people, enhancing positive emotional consequences. ${ }^{25}$

\section{Engaging in musicking for well-being}

We view well-being as a subjective state which may be influenced by various elements. We use the PERMA framework as a foundation for our view on well-being. ${ }^{18}$ It states that well-being consists of five elements: (1) positive emotions, (2) engagement, (3) relationships, (4) meaning and (5) accomplishment. Many of these elements have already emerged as of importance in other categories, including experiencing positive emotions, and building strong relationships. These elements of well-being are also closely reflected in the literature on musicking and well-being.

Musicking has the ability to elevate, stimulate and assist learners in various ways. ${ }^{20}$ It connects us psychologically to the world outside ourselves and facilitates the building of meaningful relationships. ${ }^{20,24,35,36}$ Musicking may also connect us with the physical body we inhabit. ${ }^{31}$

The experience we have in the musical space is reliant on the body we inhabit, our history and accessibility of the music that forms us. ${ }^{31}$ Through caring experiences of expressive movement as part of their musicking, learners are able to nourish their self-esteem. ${ }^{37,38}$ This may be particularly valuable to learners in the intermediate phase who are going through bodily changes and may feel self-conscious during this transitional period. ${ }^{39}$

Through musical participation, individuals can become more mature and secure in their personal identity. ${ }^{20,29}$ Through this process, they create a musical identity. This musical identity, in turn, creates a space for people to be there for one another. ${ }^{20,36}$ It has the potential to contribute a sense of oneness which, in turn, facilitates experiences of well-being in a person. ${ }^{20,33}$ Empowering learners to build a positive musical identity may prove helpful to their well-being far beyond the intermediate phase.

When people engage in challenging musicking activities, they become cognitively stimulated. ${ }^{26,40}$ The challenge of this cognitive stimulation may contribute to confidence building. ${ }^{20,41}$ In these instances, acquiring musicking skills may enable learners to thrive as life-long learners.

Within the social settings where life-long musicking engagement takes place, learners may build lasting bonds..$^{20,33,42}$ These relationships enhance feelings of belonging and strengthen the individual's sense of self, thereby facilitating experiences of subjective well-being. ${ }^{20,34,43,44,45,46}$ 


\section{A conceptual framework to understand the relationship between musicking and personal and social well-being for intermediate phase learners}

During the data analysis proses, the personal and social wellbeing outcomes in the CAPS document were analysed to create a set of a priori codes, which were used to code the music and well-being literature. The findings are represented in a conceptual model (see Figure 1). This analysis showed that musicking in the intermediate phase life skills classroom may be employed to teach the personal and social well-being section of the intermediate phase life skills CAPS, if the central focus of the musicking experience aligns with the cultural and moral education taught in the intermediate phase life skills classroom. The possibilities afforded through musicking form the basis for the nine propositions of our conceptual model and can be described as follows:

- Personal and social well-being can be taught through musicking in the life skills classroom if ethical knowledge and moral education are placed at the centre of the musicking experience.

- Personal and social well-being can be taught through musicking in the life skills classroom if the musicking experience facilitates self-awareness.

- Personal and social well-being can be taught through musicking in the life skills classroom if the musicking experience facilitates social awareness.

- Personal and social well-being can be taught through musicking in the life skills classroom if the musicking experience facilitates self-management.

- Personal and social well-being can be taught through musicking in the life skills classroom if the musicking experience facilitates relationship management.

- Personal and social well-being can be taught through musicking in the life skills classroom if learners have the opportunity to experience positive emotions during the musicking.

- Personal and social well-being can be taught through musicking in the life skills classroom if learners are actively engaged through musicking.

- Personal and social well-being can be taught through musicking in the life skills classroom if musical engagement is meaningful to learners.

- Personal and social well-being can be taught through musicking in the life skills classroom if learners experience a sense of accomplishment as a result of their musicking.

\section{Application to the intermediate phase life skills classroom}

In this section, we illustrate how our conceptual framework for musicking in the life skills classroom as cultural and moral education may be interpreted and applied in the intermediate phase classroom to achieve both musical and personal, and social well-being outcomes. In each example, we illustrate the application of our framework to performing arts outcomes in a specific grade in the intermediate phase.

In each term grade, four learners are required to reflect on other's performances using creative arts terminology. This is an ideal opportunity for a teacher to model social awareness, relationship management and self-management to learners. A teacher may model a feedback model such as the positive sandwich, in which two positive remarks are used to frame one critique of the performance. Alternatively, the teacher may model a simplified Socratic method by reframing critique into questions. Both of these approaches will enable the learners to become more aware of the modes of feedback they give their peers.

In term one grade, five learners are required to improvise locomotor and non-locomotor movement sequences. This is a good opportunity to also teach self-management, as learners often find it difficult to share physical space with other learners. The teacher may notice that some learners seem unaware of the way their bodies move in space or may be less aware of other learners around them. This may lead to conflict. A teacher, informed by our framework, may approach this as an opportunity to teach consideration and understanding for others' emotions, self-management and conflict management strategies. A teacher may also employ mirroring as the initial movement improvisation activity. In this activity, learners are assigned pairs. One partner takes on the role of leader, whilst the other plays the follower. The leader improvises expressive movement to recorded music, and the follower mirrors the movements as closely as possible. Usually, this activity begins with mirroring hand movements, where the partners place their palms facing each other. The teacher may choose to indicate role reversals at appropriate points in time. Mirroring encourages learners to become more aware of another person in their space. ${ }^{47}$ The exchange of leadership roles also serves in teaching learners how to contribute positively to a group experience while fulfilling different roles.

During the second term, grade six learners are required to analyse and present a cultural dance. This is an opportune moment for a teacher to encourage intercultural understanding and model compassionate listening as the learners explore the cultural dances of various groups. This outcome may also serve to sensitise the learners to musicking in the sense that Small ${ }^{1}$ describes the verb, as a means of engaging musically to illustrate and foster the ideal social relations within a given socio-cultural context.

\section{Discussion}

In this article, we discussed our conceptual framework for teaching personal and social well-being through musicking in the intermediate phase life skills classroom. In this conceptual framework, musicking is viewed as instrumental in teaching personal and social well-being when it is seen as an act of cultural and moral education. This framework leans strongly on the values of ubuntu, ${ }^{16}$ and therefore views 
musicking as a socio-cultural practice ${ }^{31}$ which may be employed to teach survival, respect and dignity, compassion and solidarity. By using musicking as a means to teach this worldview, we also assert that teachers can empower students to meet the emotional intelligence ${ }^{17}$ outcomes by facilitating musicking experiences which focus on selfawareness, ${ }^{19,31}$ social awareness, ${ }^{4,5}$ self-management ${ }^{9}$ and relationship management. ${ }^{1,19,31}$ When the nine propositions of our conceptual framework are met, musicking may facilitate experiences of subjective well-being and be instrumental in the teaching of personal and social wellbeing outcomes.

This framework has many practical implications. Firstly, this framework shows that all life skills teachers in the intermediate phase may benefit from becoming competent music facilitators, as this will add valuable skills to their repertoire. These skills may be employed to teach important outcomes in the life skills classroom. Secondly, this framework also underscores the importance of arts education in general, and music education in particular, for student teachers. This has various implications for higher education institutions, where arts education is often pushed to the curricular periphery.

\section{Conclusion}

Despite having important implications for practice and higher education curriculum design, there were some limitations in conducting this study. This study uses only literature as data. Therefore, we cannot speak about individual experiences of South African intermediate phase life skills teachers, nor can we address the very real challenges teachers face when trying to use musicking as a means to facilitate personal and social well-being in the intermediate phase life skills class. However, this opens up various exciting possibilities for future research. It is our hope that this framework may inspire educators to become more critical of the ways in which they integrate the distinct aspects of the life skills curriculum, and that by doing so, we may see future research, addressing the limitations of this study.

\section{Acknowledgements Competing interests}

The authors have declared that no competing interest exists.

\section{Authors' contributions}

R.J.M. contributed to the conceptualisation of the study and collected data and engaged in the analysis thereof. R.J.M. contributed towards all sections for the first draft and created preliminary visualisations for the article. J.M. contributed to the conceptualisation for the study. J.M. acted as the supervisor during the data collection and analysis stage and during the initial write-up. J.M. re-wrote and edited the initial write-up and changed the visualisation and conceptual framework sections.

\section{Ethical considerations}

This article followed all ethical standards for research without direct contact with human or animal subjects.

\section{Funding information}

This research received no specific grant from any funding agency in the public, commercial or not-for-profit sectors.

\section{Data availability}

The authors confirm that the data supporting the findings of this study are available within the article.

\section{Disclaimer}

The views and opinions expressed in this article are those of the authors and do not necessarily reflect the official policy or position of any affiliated agency of the authors.

\section{References}

1. Small C. Musicking: The meanings of performing and listening. Middletown, CT: Wesleyan University Press; 1998

2. Edgar SN. An ethic of care in high school instrumental music. Action, criticism, and theory for music education [homepage on the Internet]. 2014 [cited 2021 May 17];13(2):112-137. Available from: http://act.maydaygroup.org/articles/ Edgar13_2.pdf

3. McFerran KS, Crooke AH, Bolger L. Promoting engagement in school through tailored music programs. Int J Educ Arts [serial online]. 2017 [cited 2021 May 17];18(3). Available from: EbscoHost eJournals

4. Elliott DJ, Silverman M, Bowman WD. Artistic citizenship: Introduction, aims and overview. In: Elliott DJ, Silverman BWD, editors. Artistic citizenship. New York, NY: Oxford University, 2016; p. 3-21.

5. Elliott DJ. Another perspective: Music education as/for artistic citizenship. Music Educ J. 2012;99(1):21-27. https://doi.org/10.1177/0027432112452999

6. Allsup RE, Westerlund $\mathrm{H}$. Methods and situational ethics in music education. Action Critic Theor Music Educ. 2012;11(1):124-148.

7. Welch GF, Ockelford A. The importance of music in supporting the development of children with learning disabilities. Int J Birth Parent Educ. 2015;2(3):21-23.

8. Blackburn R, Bradshaw T. Music therapy for service users with dementia: A critical review of the literature. J Psychiatr Ment Health Nurs. 2014;21(10):879-888. https://doi.org/10.1111/jpm.12165

9. Spratt J. Childhood well-being: What role for education? $\mathrm{Br}$ Educ Res J. 2016;42(2):223-239. https://doi.org/10.1002/berj.3211

10. Burnard P, Dragovic T. Collaborative creativity in instrumental group music learning as a site for enhancing pupil well-being. Camb J Educ. 2015;45(3):371-392. https://doi.org/10.1080/0305764X.2014.934204

11. Goodrich A. Health musicing in a community orchestra. Int J Community Music. 2013;6(1):45-63.

12. Department of Basic Education. The CAPS document: Grade 4-6 [homepage on the Internet]. 2011 [cited 2021 May 14]. Available from: https://www.education.gov. za/Portals/0/CD/National $\% 20$ Curriculum $\% 20$ Statements $\% 20$ and $\% 20$ Vocational/ CAPS \% 20IP\% 20\%20LIFE\%20SKILLS\%20GR\%204-6\%20\%20WEB. pdf?ver=2015-01-27-161425-333

13. Jansen van Vuuren $\mathrm{E}$, Van Niekerk C. Music in the life skills classroom. Br J Music Educ. 2015;32(3):273-289. https://doi.org/10.1017/S0265051715000340

14. John W. Creswell. Research design, qualitative, quantitative and mixed methods approach. Thousand Oaks, CA: Sage; 2014.

15. Saldaña, J. Thinking qualitatively: Methods of mind. Thousand Oaks, CA: Sage; 2014.

16. Molose T, Goldman GA, Thomas P. Towards a collective-values framework of Ubuntu: Implications for workplace commitment. Entrepreneurial Bus Econ Rev. 2018;6(3):193-206. https://doi.org/10.15678/EBER.2018.060312

17. Segon $M$, Booth $C$. Virtue: The missing ethics element in emotional intelligence. J Bus Ethics. 2015;128(4):789-802. https://doi.org/10.1007/s10551-013-2029-z

18. Seligman M. PERMA and the building blocks of well-being. J Positive Psychol. 2018;13(4):333-335. https://doi.org/10.1080/17439760.2018.1437466

19. Schwandt TA. The Sage dictionary of qualitative inquiry. Thousand Oaks, CA: Sage. 2014.

20. Ansdell, G. How music helps in music therapy and everyday life. 2nd ed. London: Routledge; 2016. 
21. DeNora T. Music in everyday life. Cambridge: Cambridge University Press; 2000.

22. Noddings N. Moral life and education. Action Teach Educ. 2016;38(3):212-216 https://doi.org/10.1080/01626620.2016.1194783

23. Bunt L. Music therapy: A resource for creativity, health and well-being across the lifespan. In: Odena O, editor. Musical creativity: Insights from music education research. London: Ashgate, 2012; p. 165-181.

24. Croom AM. Music, neuroscience, and the psychology of well-being: A précis Front Psychol. 2012;2:393. https://doi.org/10.3389/fpsyg.2011.00393

25. Croom AM. Music practice and participation for psychological well-being: A review of how music influences positive emotion, engagement, relationships, meaning, and accomplishment. Musicae Scientiae. 2015;19(1):44-64. https://doi. org $/ 10.1177 / 1029864914561709$

26. Creech A, Hallam S, McQueen $H$, Varvarigou M. The power of music in the lives of older adults. Res Stud Music Educ. 2013;35(1):87-102. https://doi.org/10.1177/ $1321103 \times 13478862$

27. Clennon O, Boehm C. Young musicians for heritage project: Can a music-based heritage project have a positive effect on well-being? Music Educ Res. 2014;16(3) 307-329. https://doi.org/10.1080/14613808.2014.909395

28. Carruth EK. The effects of singing and the spaced retrieval technique on improving face-name recognition in nursing home residents with memory loss. J Music Ther 1997;34(3):165-186. https://doi.org/10.1093/jmt/34.3.165

29. Habron J, Butterly F, Gordon I, Roebuck A. Being well, being musical: Music composition as a resource and occupation for older people. Br J Occup Ther. 2013;76(7):308-316. https://doi.org/10.4276/030802213X13729279114933

30. Västfjäll D, Terry PN, Hartig. Music, subjective well-being and health: The role of everyday emotions. In: MacDonald R, Kreutz G, Mitchell L, editors. Music, health, and well-being. New York, NY: Oxford University Press, 2012; p. 1-34.

31. Elliott DJ, Silverman M. Why music matters: Philosophical and cultural foundations. In: MacDonald R, Kreutz G, Mitchell L, editors. Music, health, and well-being. New York, NY: Oxford University Press, 2012; p. 942-1447.

32. Van der Merwe L, Habron J. The Dalcroze diamond: A theory of spiritual experiences in Dalcroze Eurhythmics. Music Educ Res. 2019;21(4):426-440. https://doi.org/10.1080/14613808.2019.1612340

33. Saarikallio $S$. Cross cultural approaches to music and health. In: MacDonald $R$ Kreutz G, Mitchell L, editors. Music, health, and well-being. New York, NY: Oxford University Press, 2012; p. 1-30.

34. Clift S. Singing, well-being and health. In: MacDonald R, Kreutz G, Mitchell L, editors. Music, health and well-being. New York, NY: Oxford University Press, 2012; p. 1-20.
35. Hallam S, Creech A. Can active music making promote health and well-being in older citizens? Findings of the music for life project. London J Prim Care. 2016;8(2):21-25.

36. Van der Merwe J. 'We make a song': Moving beyond active music-making in the Field Band Foundation. Int J Community Music. 2017;10(2):121-138. https://doi. org/10.1386/ijcm.10.2.121_1

37. Murcia $C Q$, Kreutz G. Dance and health: Exploring interactions and implications. In: MacDonald R, Kreutz G, Mitchell L, editors. Music, health and well-being. New York, NY: Oxford University Press, 2012; p. 1-22.

38. Norton K. Singing and well-being: Ancient wisdom, modern proof. New York, NY Routledge. 2016.

39. Lindberg SM, Hyde JS, McKinley NM. A measure of objectified body consciousness for preadolescent and adolescent youth. Psychol Women Q. 2006;30(1):65-76. https://doi.org/10.1111/j.1471-6402.2006.00263.x

40. Bugos JA, Perlstein WM, McCrae CS, Brophy TS, Bedenbaugh PH. Individualized piano instruction enhances executive functioning and working memory in older
adults. Aging Ment Health. 2007;11(4):464-471. https://doi.org/10.1080/1360 adults. Aging Mer
7860601086504

41. Ockelford A, Markou K. Music education and therapy for children and young people with cognitive impairments: Reporting on a decade of research. In MacDonald R, Kreutz G, Mitchell L, editors. Music, health, and well-being. New York, NY: Oxford University Press, 2012; p. 1-41.

42. Higgins L, Willingham L. Engaging in community music: An introduction. New York, NY: Routledge; 2017.

43. Davidson J, Emberly A. Embodied musical communication across cultures: Singing and dancing for quality of life and well-being benefit. In: MacDonald R, Kreutz $G$, Mitchell L, editors. Music, health, and well-being. New York, NY: Oxford University Press, 2012; p. 1-27.

44. Hampshire KR, Matthijsse M. Can arts projects improve young people's wellbeing? A social capital approach. Soc Sci Med. 2010;71(4):708-716. https://doi. org/10.1016/j.socscimed.2010.05.015

45. North AC, Hargreaves DJ. Pop music subcultures and well-being. In: MacDonald R, Kreutz G, Mitchell L, editors. Music, health, and well-being. New York, NY: Oxford University Press, 2012; p. 1-23.

46. Gembris H. Music-making as a lifelong development and resource for health. In: MacDonald R, Kreutz G, Mitchell L, editors. Music, health, and well-being. New York, NY: Oxford University Press, 2012; p. 1-29.

47. Van der Merwe L, Tempelhoff JW, Joubert D. Exploring the meanings that stakeholders of the Brandfort community ascribe to their experiences of a Dalcroze-inspired workshop. Int J Community Music. 2019;12(2):249-267. https://doi.org/10.1386/ijcm.12.2.249_1 